\title{
EL HUMANISMO HOLÍSTICO. UNA ALTERNATIVA ESPIRITUAL PARA LA UNIVERSIDAD LATINOAMERICANA (REFLEXIÓN TEÓRICA)
}

\author{
HOLISTIC HUMANISM, A SPIRITUAL ALTERNATIVE FOR THE \\ LATIN AMERICAN UNIVERSITY (THEORETICAL REFLECTION)
}

\author{
SONIA Elena LóPEZ PULGaRÍN*
}

Recibido: 20 de agosto de 2017 - Aceptado: 20 de septiembre de 2017 - Publicado 31 julio de 2018 DOI: $10.24142 /$ raju.v13n26a7

\section{Resumen}

A partir de mis experiencias como docente he podido elaborar un aprendizaje que pongo al servicio de la academia; hoy comprendo que el humanismo puede ser abordado desde dos perspectivas: desde el Cristianismo o Medioevo o desde el acercamiento integral y holístico. Es así como ambas se enlazan para entrar en terrenos no abordados por los conceptos teóricos. He percibido que cuando en el aula de clase se usan perspectivas propias y ancestrales de Latinoamérica los estudiantes obtienen una visión espiritual en sus vidas, surgen

Trabajadora Social, Universidad Pontificia Bolivariana, Medellín, Colombia. Especialista en Trabajo Social Familiar, Universidad Pontificia Bolivariana. Magíster en Educación, Tecnológico de Monterrey, México. Doctora en Humanidades, Corporación Universitaria Minuto de Dios, UNIMINUTO. Trabajadora Social, docente de la Corporación Universitaria Minuto de Dios de la Facultad de Ciencias Humanas y Sociales, Seccional Bello, Colombia.

Correo electrónico: slopezpu@uniminuto.edu.co 
elementos de transformación y cambio en sus contextos inmediatos y asumen compromisos para proyectar esos nuevos sentires.

Palabras clave: humanismo, holismo, transformación propia, Latinoamérica, círculos del amor.

\section{Abstract}

From my experiences as a professor I have been able to develop an apprenticeship that I put at the service of the academy, today I understand that humanism can be approached from two perspectives: from Christianity or Middle Ages or from the holistic and integral approach. This is how both are linked to enter grounds not addressed by theoretical concepts. I have noticed that when Latin American students use their own and ancestral perspectives in the classroom, they obtain a spiritual vision in their lives, elements of transformation and change emerge in their immediate contexts and assume commitments to project these new feelings.

Keywords: Humanism, Holism, Transformation, Latin America, Circles of love. 
El humanismo holístico. Una alternativa espiritual para la universidad latinoamericana (reflexión teórica)

\section{INTRODUCCIÓN}

El humanismo, entendido como la visión y comprensión de la dignidad desde el momento en que surge como concepto cristiano, permite dar luz al conocimiento de las capacidades innatas de las personas, comprender que solo a partir del siglo XIV se veía la bondad como una cualidad o atributo que permitiría nombrar al otro desde su ser.

Estar acompañando la formación profesional de una disciplina de las Ciencias Humanas y Sociales en una universidad de carácter confesional y religiosa, me ha permitido reconocer que el humanismo cristiano puede ser entendido y abordado desde otras dimensiones. El enfoque que presenta la Corporación Universitaria Minuto de Dios (UNIMINUTO), llamado "praxeología", también ha posibilitado hacer abordajes que van más allá de la teoría y logran concretar, a partir de las prácticas, nuevas formas de comprensión de las realidades que viven los estudiantes.

El modelo de UNIMINUTO permite combinar teorías europeas, prácticas orientales y las nuevas miradas decoloniales, llamadas hoy pensamiento latinoamericano, para llevar una visión integral y holística a los estudiantes que provienen de estratos 1 y 2 y con conocimientos empíricos muy valiosos por sus historias y saberes.

A riesgo de combinar elementos propios de la cultura latinoamericana, teorías europeas y norteamericanas y filosofías orientales que permitan combinar ejercicios de observación para comprender e interpretar las complejas dinámicas sociales que nos rodean. Prácticas como la danza, los símbolos, la meditación, el juego, los mándalas, las diferentes expresiones artísticas y culturales autóctonas evidencian la percepción de los estudiantes de su mundo, de su relación con las cosas, con los hechos y las historias de sus ancestros, padres, familiares, amigos, vecinos. Todo esto permite tener una filigrana de hilos invisibles que se trenzan en su mente y cuerpo para potenciar una transformación personal y ampliar su visión del entorno inmediato, con una memoria ancestral que despierta en pequeños o grandes chispados que podrían llamarse inteligencia espiritual.

\section{HUMANISMO HOLÍSTICO}

Hablo entonces de un nuevo y viejo humanismo, el "humanismo holístico", un humanismo propio o emancipador más allá de lo poscolonial, 
que rescata la importancia y la esencia del ser, que estuvo sin ser nombrado pero sentido, tocado, olido, respirado, cicatrizado, enterrado, inaugurado, porque no desenterrado y revivido. Evocando a De Sousa (2010), que dice que hasta ahora ha predominado la forma occidental de entender el mundo, "hay una necesidad de aprender otros conocimientos sin olvidar el de uno mismo" (p. 52), lo que llama la "ecología de los saberes" que se esgrime por la necesidad de reconocimiento de la diversidad epistemológica del mundo y como un paso hacia la justicia de los saberes y el conocimiento que da la posibilidad de articular diferentes teorías, no solo las clásicas europeas occidentales, sino otras orientales y unas propias de construcción, con base en nuestra historia y realidades, que parten de una mirada que se acerca a una dimensión política transformadora y que permiten vernos desde diferentes lugares de participación en la historia del mundo.

Estas teorías decoloniales, sustentadas en una tendencia sociocrítica latinoamericana, surgida en la década de los noventa, que ya tenía visos y fortalezas en los años setenta desde un movimiento llamado reconceptualización, y que ha sido conformada por intelectuales y activistas de movimientos sociales como Enrique Dussel, Walter Mignolo, Aníbal Quijano, Arturo Escobar, Oscar Guardiola, Catherine Walsh, Norma Fóscolo, Santiago Castro, José Mariátegui, Antonio Guadarrama, entre otros, quienes habían retomado elementos de la educación popular, la teoría de la dependencia, los estudios culturales y la teología de la liberación.

Todas estas propuestas permiten hacer una invitación a reconocer que la América ya estaba construida y civilizada desde antes de la invasión europea. El holismo va a dejar que se esclarezca lo dicho y lo silenciado, lo que vemos pero no visibilizamos, que problematice y desnaturalice las relaciones de poder como nos propone Paulo Freire. Todo esto posibilita evocar una comprensión e interpretación de las realidades desde su amplio espectro, complejo y diverso, y poder no solo soñar, sino concretar el logro de "una genuina democracia social global".

Teorías como la hermenéutica, la fenomenología, la etnometodología, la etnografía, el interaccionismo simbólico, el constructivismo, el construccionismo social, el pensamiento complejo, el existencialismo (con sus dos corrientes una pesimista o nihilista y otra romántica y optimista), son elementos que han surgido desde el humanismo contemporáneo como la logoterapia, la resiliencia, la autotrascendencia o trascendencia, la gestal y las teorías que se desprenden del pensamiento de Carl Jung, que podría considerarse uno de los pioneros del holismo y lo que hoy se está gestando 
como el trabajo social espiritual. Son todos elementos que permiten, a partir de la teoría, crear vivencias en el aula con ejercicios y técnicas didácticas para llevarlas al espacio de lo vivido, la reflexión profunda de la existencia y de conocer y develar nuestras raíces indígenas, negras, mestizas y criollas en lo que hoy venimos a hacer y darle un sentido a la existencia propia y a la de los demás.

Partir del todo a las partes y volver de las partes a un todo es hacer lecturas profundas de nuestras propias realidades; llegar a ser el texto para vernos dentro del contexto y hacer parte del contexto para llegar a ser el texto, comprender el significado de los rituales, las creencias, las tradiciones, el lenguaje, los símbolos, la cultura, la cotidianidad y la vida misma es la mayor riqueza en una parte del planeta que se llama Latinoamérica, región rica en formas diversas de vida, llena de relaciones exquisitas por sus formas, riquezas, colores, músicas, historias de amor y odio, dolor, violencia, muerte y sobrevivencia, donde cada día se debate, desde orillas opuestas de un mismo río, la vida y la muerte, la miseria y las celebraciones de días históricos, de masacres de héroes no reconocidos y no propios, de la relación directa del hombre y la mujer con la naturaleza.

La holística se convierte en el conjunto de elementos teóricos y prácticos que, de manera articulada, brindan las bases para lograr una comprensión amplia del ser humano, no solo desde su psiquis, sino desde su dimensión más profunda, la dimensión espiritual; por eso se convierte en una alternativa viable para conocer lo real de nuestro ser interno. Como dice Claudio Naranjo (2007): "Porque cuando me veo en mi auténtica perspectiva comienzo a hacerme sabio de mi propia vida" (p. 157).

Esa sabiduría habita en cada ser sin que, necesariamente, seamos conscientes de ella, solo que encontramos respuestas y salidas desde el instinto y desde la voluntad. Voluntad que nos lleva a vivir de formas realmente humanas y biológicamente evolucionadas para respetarnos y protegernos unos a otros.

El humanismo holístico es una propuesta alternativa pues va más allá de lo intelectual o académico, porque posibilita potenciar la capacidad de amar, de usar la holística en la educación; es una salida para la contemporaneidad ya que se puede recrear por medio de ejercicios que conectan a los estudiantes con espacios no convencionales, con el aquí y el ahora. Es una opción de caminar de forma consciente para estar en el presente.

Solo el presente es lo real, y eso es algo que las personas que se disponen y se dejan tocar vibran, consienten para hacer el trabajo de sanar sus heridas reconocerse, aprender y replicar. 
La humanidad se convierte en más humana, se hace más digna en la medida en que comunica o entra en comunión con otros de forma real y genuina. Esta capacidad de abrirse tiene una dimensión ética y ontológica, implica el respeto por la diversidad, la promoción del diálogo intercultural y la conciencia de la radical unidad del género humano basada en la idéntica dignidad de toda persona.

Concretar elementos como el dolor, la pérdida, lo viejo y la muerte, tan cercana por los fenómenos de violencia social, el desplazamiento obligado, el hambre y la pobreza que ha logrado labrar en nosotros un duelo inconcluso de más de cinco siglos.

Tener la capacidad de poder hablar y mirarse desde adentro para perder la vergüienza de lo que no fuimos culpables y cargamos a cuestas en un proceso de colonización que no termina, una profesión con un peso moral por cómo se concibió y se negó, en donde ayudar fue una virtud y hoy sabemos que es un impedimento para el cambio.

Observar que existen estudiantes que logran transformar sus vidas a partir de una experiencia inducida por su percepción del mundo, sin caer en el mero optimismo o en las técnicas rápidas de "soluciónelo usted mismo", sino con el encuentro de lo profundamente vivido como base de una elaboración para el cambio, del "darse cuenta" para que en el Aquí y el Ahora la vida se concrete como un asunto profundamente espiritual, encontrando la esencia de las cosas, como invita Hegel en la Fenomenología del espíritu. Y saber que los aportes que hacen Marx y Habermas nos invitan a saber que la religión puede ser usada para enajenar a las personas, para que en sus búsquedas puedan entender que pueden suceder cambios internos como despertar a la conciencia cósmica, a dejar que sucedan los milagros, que son pequeñas o grandes transformaciones.

\section{LATINOAMÉRICA}

Se podría hablar hoy, en Latinoamérica, de un híbrido o pluralismo de corrientes donde la tolerancia al mundo filosófico y a las posturas originarias, desde otras visiones, han permitido construcciones electivas, más no necesariamente eclécticas. Hoy se visibiliza una apertura en el medio académico donde profesionales de diversas corrientes pueden trabajar, de manera articulada, orientando una misma asignatura. Esta apertura latina hace que se construya una riqueza no solo en el campo del conocimiento, sino en el quehacer y en la reflexión intelectual. 
Existe una relativa independencia de las formas ideológicas que permite una comprensión respecto a lo que somos; pero hay un conocimiento profundo que los estudiantes no saben que poseen y que está grabado en su inconsciente colectivo, como diría Jung: se encuentra en el instinto, en lo que de manera muy propia llamamos "malicia indígena". No en vano hemos adquirido fama de ser personas hábiles para movernos, pero no tanto como para valorar lo que somos en esencia, porque de ser así no hubiéramos copiado modelos desarrollistas impuestos pensando que debíamos alcanzar a Europa y llegar a ser como ellos.

Ladislao Landa (2011), desde su texto Pensamientos indígenas en nuestra América, ilustra a Latinoamérica anotando que:

La oligarquía dominante era reacia a la presencia de varios sectores que el país albergaba (indígenas, negros e inmigrantes); frente a esta negativa, fueron las clases medias las que destacaron la presencia de estos ausentes, y forjaron una especie de bandera para la comprensión de una formación completa de la sociedad nacional (p. 35).

En este texto habla varias veces de una sociedad civil, argumentando que: "solo era posible, según la perspectiva de este grupo de indigenistas independientes, considerando a uno de los bastiones de la nación, los indios" (p. 35).

Por su parte, el autor colombiano Arturo Escobar (2014) plantea que es posible invertir las lógicas establecidas por las jerarquías del conocimiento; que las propuestas de algunos movimientos sociales (indígenas, afrodescendientes, ambientalistas, campesinos y de mujeres) sobre las cuestiones de la tierra y el territorio están a la vanguardia del pensamiento sobre estos temas y de algunos otros como la autonomía alimentaria, la soberanía del agua y los modelos alternativos de desarrollo; y que no son rezagos del pasado ni expresiones románticas que la realidad se encargará de desvirtuar. Pero también tiene cabida la metafísica nuevamente cuando el método científico no puede abordar experiencias espirituales y hay que recurrir a reconocer lo especial de nuestra naturaleza humana y de la madre tierra.

La dimensión de la madre tierra, la crisis ecológica, saber que todo ser vivo es la expresión de la fuerza creativa de la tierra, de su autoorganización y de la constate emergencia, los pueblos étnicos en la defensa de la madre tierra, futuristas sintonizadas, la crisis ecológica, transición ecológicas. Órdenes socio naturales un camino para que los humanos, los animales y las 
plantas puedan coexistir de forma mutuamente enriquecedora, trascendiendo a los modelos capitalistas.

Surgen en espacios como: la ecología, las ciencias de la complejidad, la espiritualidad, el pensamiento alternativo del desarrollo y la economía, la academia crítica y los movimientos sociales que imaginan una transición civilizatoria.

Fals Borda también nos sedujo a sentir pensar con el territorio óseo a sentir con el corazón y pensar de la mente, pensar desde el corazón. Y co-rrazonar así como lo hicieron los movimientos saociales de Chiapas inspirados en la experiencia zapatista de México.

Para entender el movimiento indianista podemos acercarnos a otros documentos significativos que definen su ideología, pensamiento o doctrina. Por ejemplo, la Declaración de Quito - documento importante del movimiento indio ecuatoriano- que anuncia que el encuentro de 1990 representa la conciencia de "500 años de Resistencia" (Landa, 2011).

Los redactores de este documento no anuncian explícitamente el indianismo como pensamiento político, aunque asumen representar a 120 naciones, tribus y organizaciones indígenas de veinte países de América, lo que supone una política pan-indianista. Cultivamos en comunidad y distribuimos los frutos en comunidad. Bonfil, como es sabido, fue uno de los antropólogos que impulsó las dos primeras reuniones de Barbados en la década de los setenta. Este antropólogo mexicano fue uno de los más entusiastas propulsores del indianismo. Criticó, junto con otro grupo de antropólogos, la política integracionista del Instituto Indigenista en México (Pensamientos indígenas en nuestra América (Declaración de Quito, 1990) citada por Landa, 2011).

De acuerdo con el texto Pensamiento filosófico latinoamericano. Humanismo, método e historia Guadarrama (2012) señala que hay tres actitudes respecto al ámbito filosófico latinoamericano; una es la mirada hermenéutica, otra es la liberadora o emancipadora y la otra podría llamarse dialéctico-materialista; todas presuponen una búsqueda históricamente ubicada. Me arriesgo a decir que en el hacer, tanto como en la educación, también existen estas tendencias, y considero que es posible encontrar posturas que logren articular las tres y respeten la visión de religión y filosofía, y permitan tener un despertar espiritual que puede ir más allá para transformar el pensamiento latinoamericano desde la formación universitaria. Para muchos filósofos contemporáneos la filosofía y el conocimiento habían llegado a Latinoamérica con Colón, borrando toda la sabiduría ancestral. 
El humanismo holístico. Una alternativa espiritual para la universidad latinoamericana (reflexión teórica)

Desde hace más de 600 años antes de Cristo tenemos vestigios y conocimiento de las culturas indígenas americanas, con una herencia y tradición mezclada desde occidente y oriente que, finalmente, se concretó en creencias y tradiciones basadas en un profundo animismo, convencidos de que todo ser es animado, viviente y contiene un espíritu (ánima).

La sabiduría está en dejar que las cosas ocurran, más que en tratar de hacer que las cosas sucedan. Rendirse para ganar, soltar las riendas, dejarse llevar, soltar el control. Paradojas de la vida que posibilitan una vida serena, útil y feliz.

Los indígenas amerindios comparten con los taoístas del lejano oriente un profundo respeto por la naturaleza, la vida en todas sus formas es un maestro perfecto; la naturaleza es sagrada, todas las cosas tienen vida y espíritu propio.

Muchas leyendas recuerdan una especie de edad de oro en que animales y humanos viven en armonía y en un diálogo permanente, cada uno aprendiendo del otro.

Si todo es santo alrededor nuestro, los primeros americanos supusieron que era el lugar para explorar un poder divino. En la búsqueda de un espíritu guardián, común a varias tradiciones indígenas, todas estas creencias terminan siendo similares a rastreos de un espíritu superior que está afuera, pero que también está dentro de cada ser animado; la pregunta, en última instancia, es de orden filosófico, pero permite tener vivencias que pueden ser recordadas para lograr una reconexión con el mundo de lo vivido. Los espacios académicos en la universidad latinoamericana pueden producir una deconstrucción y una construcción desde lo simbólico y desde el lenguaje para lograr nuevas formas de relación, y llevarlas a prácticas que permitan no perpetuar el poder y la tiranía aprehendida en el periodo de la conquista y la colonia, prácticas que separan y dividen y logran marcar grandes diferencias impuestas desde lo hegemónico y lo patriarcal.

Como los indígenas amerindios, los egipcios creyeron que las grandes fuerzas de la naturaleza eran espíritus, incluyendo el cielo, la tierra, el sol, el agua; de igual forma, le dieron una especial creencia a la vida después de la muerte.

En palabras de Pío Jaramillo Alvarado (1993), quien en 1943 planteaba en un congreso indigenista:

¿Existe el indio?... ¿Pero es posible que pueda discutirse la existencia del indio? No es del indio como factor étnico lo que se discute, pues 
su existencia es real, y su número en toda América es de millones... sino que lo que se averigua es... ¿existe el indio en el espíritu de las naciones americanas, o prevalece el espíritu europeo? ¿Es el indio y su mestizaje con el blanco, con el negro y con el chino lo que da su tonalidad a la cultura indoamericana, y en qué grado afectan a esa tonalidad las responsabilidades históricas que tiene América en la cultura del mundo? Esta es la cuestión. Y la respuesta es afirmativa, en forma categórica: el indio existe... pese a todos los hibridismos de las razas, al mestizaje de tono más o menos blanco o bronceado, y a los prejuicios (p. 457).

Bendiciones y maldiciones, bondad y maldad, construcción y destrucción, dar y recibir, víctima y victimario, tirano y obediencia ciega, son relaciones constantes que enaltecen y abandonan la creencia de un dios o unas diosas (Guadarrama, 2012). "El profundo amor que sentía por los hombres no empañó la mirada para descubrir sus imperfecciones que, según él, solo el hombre mismo podía erradicar sin necesidad de la custodia divina" (p. 44).

Esclarecer la fusión de lo soñado y lo concreto, de lo que conocemos y lo que aún no imaginamos, permitir que las cosmovisiones nublen la idea de lo perfecto, dado por explicaciones religiosas:

La miseria religiosa es, por una parte, la expresión de la miseria real y, por otra, la protesta contra ella. La religión es el suspiro de la criatura oprimida, el corazón de un mundo sin corazón, el espíritu de una situación carente de espíritu. Es el opio del pueblo (Marx, 1969, p. 378).

Así, Reinaga considera que el indianismo es una "tercera fuerza en el escenario político" de la Bolivia de los años setenta. Entonces, la propuesta indianista sobre el cambio social, según dicho autor, debería ser la siguiente:

a) Nuestra Revolución no es una "revolución comunista" pro-soviética, pro-china o pro-cubana; no. Nuestra Revolución no tiene ningún "pro". b) Los indios no somos "campesinos" de la calaña del Gral. Barrientos Cantinflas y sus ladillas [pacto campesino]. No somos "campesinos" que integran la sociedad del cholaje blanco-mestizo. Eso no somos. c) Nosotros somos indios; hijos de Pachacutej, Tupaj Amaru, Tomas Katari, Tupaj Katari, Pablo Atusparia, Zarate Willka. Somos de tal trigo tal pan. Y nuestra Revolución es nuestra Revolución: una Revolución India! [...] La Revolución India, en el plano mundial, es la Revolución del Tercer Mundo [...] El Tercer Mundo 
El humanismo holístico. Una alternativa espiritual para la universidad latinoamericana (reflexión teórica)

es el África negra y amarilla Asia esclavas; y en América es el indio, el hombre salido del Anáhuac y Tiwanaku; el hijo de Moctezuma y de Manco Kapaj [...] La Revolución Francesa (1789) y la Revolución Rusa (1917) no han liberado al hombre. La 3ra Revolución, la Revolución India es quien tiene que liberarlo. La Revolución del Tercer Mundo es la última. Es ahora cuando: o triunfa o desaparece el hombre (Reinaga, 1970, p. 77 y Landa, 2011, pp. 48-49).

Detrás de la muerte de Dios se escucha todavía el "seréis como dioses" del libro del Génesis. Dice Zaratustra, profeta del nihilismo nietzscheano:

Pero, para abriros mi corazón de par en par, a vosotros, amigos. Si hubiera dioses, y ¿cómo soportaría yo no ser Dios? Luego, no hay dioses. He sido yo quien ha sacado esta consecuencia, pero ahora ella me arrastra a mí (Nietszche, 1979, p. 11).

El nihilismo, según Nietzsche es la devaluación de todos los valores, que los valores supremos se han desvalorado el considera que la cultura occidental, desde sus inicios, ha interpretado el sentido de la existencia humana desde una perspectiva trascendente.

\section{TRANSFORMACIÓN PROPIA}

Durante siglos, culturas enteras han tratado a las transformaciones internas como un aspecto necesario y deseable de la vida. Como una experiencia depuradora. Muchas sociedades desarrollaron rituales sofisticados y prácticas de meditación como maneras de invitar y estimular el crecimiento espiritual. La humanidad ha atesorado las emociones, visiones y percepciones relacionadas con el proceso del despertar en pinturas, poesías, novelas y música, y en descripciones que brindaron los místicos y profetas. Algunas de las contribuciones del arte y la arquitectura más hermosas y valoradas celebran estos dominios místicos. Para algunas personas el viaje de transformación en su desarrollo espiritual se convierte en una experiencia de carácter místico y religioso.

Parafraseando a Arias (2015): ciencia y espiritualidad se están acercando cada vez más, a medida que se corren los velos de la física cuántica y los mecanismos inconscientes salen a la luz, para poder modificarlos. Nuestros cerebros tienen la gran ventaja de estar interconectados todo el tiempo, 
por eso son estructuras orgánicas holísticas. La transformación es una toma de conciencia en un momento dado de la vida, a partir de experiencias que pueden llamarse pequeños o grandes chispazos de luz o despertares espirituales que dan una mirada diferente de la vida en el presente, sin rasgos de odio o resentimientos del pasado o los miedos y expectativas del futuro.

La palabra espiritualidad debería reservarse para situaciones que entrañan una experiencia personal que le dan a la existencia una cualidad numinosa. Jung utilizaba el término numinoso para describir una experiencia de lo sagrado, lo santo o lo extraordinario. La espiritualidad es algo que caracteriza la relación del individuo con el universo, y no requiere de una estructura formal, un ritual colectivo o la mediación de un sacerdote. En contraste, la religión es una forma de actividad grupal organizada que puede o no conducir a una verdadera espiritualidad; de acuerdo con el grado en que provea un contexto propicio para el descubrimiento personal, de una percepción consciente y genuina de la realidad desde el campo de lo subjetivo. El descubrimiento de la propia naturaleza divina puede conducir a una forma de ser, tanto a escala individual como colectiva, incomparablemente superior a lo que se considera normal.

El desarrollo espiritual es una capacidad de evolución innata en todo ser humano. Es un movimiento que fluye y lleva a la unidad; a lo que a veces se ha llamado un viaje al interior de sí mismo; es la posibilidad del autodescubrimiento de nuestro verdadero potencial. Tan común y natural como el nacimiento, es una parte integral de nuestra existencia. Es como la complicación de un proceso de evolución que lleva a una forma de vida más madura y sensata. De acuerdo con este punto de vista, la humanidad es una parte integral de la energía creadora y la inteligencia del cosmos y es, de alguna forma, idéntica y conmensurable con él.

De nuevo Arias (2015) llama la atención de cómo las interacciones humanas no son guerras ni juegos. Son canales de reconocimiento, extensión, conocimiento y crecimiento continuo. Por eso, permanecer en el presente es como un elixir mágico, y el cerebro y su función principal (mental) acompañan el proceso cuando elegimos pensar y actuar a nuestro favor, protegiendo nuestra integridad, Mente, cuerpo y espíritu sin separarse y sin justificar la división cartesiana que aprendimos hace ya muchos años y que, en gran medida, sigue limitando la visión holística del ser como líder y protagonista de su propia experiencia.

Todos los seres humanos hemos buscado una salida o un refugio, sea para la trascendencia o la religiosidad mirada como una urgencia espiritual, 
sea un amigo, un chamán, un sacerdote, un objeto inanimado que llene un vacío interior que no tiene una explicación razonable. A través de la historia se han dado momentos de esa búsqueda, y las respuestas están relacionadas con lo divino, esa explicación la trato de esclarecer la iglesia católica con el cristianismo pero no ha logrado llenar ni satisfacer esa necesidad, sus contradicciones internas, para ellose profeso un humanismo que busca romper un imaginario de muerte y destrucción. Luegoel renacimiento lo intenteara con todo el florecimiento del arte y la figura humana, después la modernidad con la ilustración y la secularización y la autonomía absoluta del hombre, sumada a la racionalidad como única forma de comprender el mundo, pero tampoco han sido suficientes para que se encuentre un sosiego a la búsqueda de un sentido nuevo a la misma humanidad. Secularización no equivale a pérdida del sentido religioso.

El proceso de secularización entendido en forma fuerte lleva, utilizando el famoso concepto de Max Weber, al desencantamiento del mundo. Sentimiento que perdura y anima a la fatalidad.

Según Nietzsche, el hombre no puede vivir sin valores. Si el mundo basado en la trascendencia se ha venido abajo el hombre debe crear nuevos valores. Así nace el super- hombre, que es un nuevo modelo de hombre, que toma conciencia del nihilismo y de su superación. Dice Zarathustra: "Yo os anuncio al ultrahombre".

El hombre es algo que debe ser superado. (“¿Que habéis hecho vosotros para superarlo?". El hombre tiene deseos de trascendencia. Hasta este momento, la trascendencia se personalizó en Dios. Pero ahora debe trascender hacia sí mismo y hacia el mundo terrenal. Desaparecido el sentido trascendente de la existencia, el super-hombre se yergue en el nuevo sentido de la tierra:

El hombre es una cuerda tendida entre el animal y el ultra hombre: una cuerda tendida sobre el abismo. Un peligroso pasar al otro lado, un peligroso permanecer en el caminar, un peligroso mirar hacia atrás, un peligroso estremecerse y pararse. La grandeza del hombre está en ser un puente y no una meta: lo que hay en el digno de ser amado es que es un tránsito y no un ocaso (Nitszche, 1979, p. 7).

El super-hombre es un nuevo estado de la humanidad. Sera capaz de decir sí a la vida, no despreciar su cuerpo, no amará al prójimo sino al amigo. Capaz de mirarse a sí mismo en el ejercicio del bien y el mal, y de crear su ley y obedecer a su propia voluntad. 
La vida, más que pensamiento, quiere ser hoy acción, esto es combate. El hombre contemporáneo tiene necesidad de fe. Y la única fe que puede ocupar su yo profundo, es una fe combativa. No volverán, quién sabe hasta cuándo, los tiempos de vivir con dulzura (Mariátegui, 1972, pp. 21-22).

Estas frases corresponden a dos concepciones de la vida. En El hombre y el mito, escrito una semana después de El alma matinal y otras estaciones del hombre de hoy, Mariátegui (1979) vuelve sobre el eje de su reflexión:

Ni la razón ni la ciencia pueden satisfacer toda la necesidad de infinito que hay en el hombre. La propia razón se ha encargado de demostrar a los hombres que ella no les basta. Que únicamente el mito posee la preciosa virtud de llenar su yo profundo (p. 75).

La transformación propia es la forma de retar la historia para demostrar la lealtad a nuestros antepasados amerindios, a los sabios del camino que hoy transitamos y vamos dejando para liberarnos desde el centro de nosotros mismos, donde habita la esencia de lo que somos como latinoamericanos.

\section{CíRCULOS DEL AMOR}

Los círculos del amor son una práctica ancestral y legendaria que nació en las culturas aborígenes de África y Latinoamérica; una forma innata de congregarse para celebrar la vida y la muerte o para transmitir los conocimientos y secretos frente a los cambios y los poderes de la naturaleza. Esta forma de encuentro se convierte, para mi clase, en una alternativa holística, en una estrategia metodológica que permite reconectar a las personas con su esencia vital; es un método terapéutico con un propósito y unos pasos a seguir para lograr articular las piezas de un todo que se ha separado a partir de una ruptura con un ser superior o una divinidad que representa la unidad en el mundo, y que permite consagrar un flujo interno del amor por los demás y por nosotros mismos.

Tomar conciencia de los miedos, de la ira y del dolor permite sanar y encontrar el verdadero lugar en el mundo. Cuando dos cosas se unen generan conciencia; el hecho de celebrar y reunirse en torno a la vida o la muerte, a conmemorar y recordar, posibilita que la creación fluya y se ejecuten movimientos para desmontar los miedos al cambio; como recrea Arias (2015): 
Suceden procesos químicos en el cerebro que ayudan a segregar oxitocina en el organismo a medida que reforcemos la creencia en una fuerza superior de la conciencia, y por tanto influye en el pensamiento y la actitud. Además, una vez que se da una cadena de elecciones y observamos sin juzgar patrones nocivos de comportamientos inconscientes en nosotros y en los demás.

Habremos sentado las bases para difundir el amor. Es importante recordar que ningún cambio es inmediato. Puede ocurrir una transformación súbita en un tiempo relativamente corto, pero lo más indicado para el espíritu es dejar que las cosas tomen su propio cauce.

El dolor, la ansiedad, la tristeza crónica y profunda no solo son sentimientos, sino síntomas contemporáneos de una separación del ser, de un gran vacío existencial, de una pérdida de sentido en algunas personas desde su infancia y por lo cual las relaciones humanas no fluyen, se tiranizan y buscan llenar a partir de otras personas, lugares y cosas, no circula de manera espontánea, el instinto natural de tomar conciencia de la unidad y la conectividad con el mundo y la naturaleza.

Para los seres humanos es entonces necesario buscar caminos y encontrar respuestas para sanar la herida emocional histórica que todos llevamos, la propuesta del método es posibilitar un reencuentro consigo mismo, es develar la necesidad de volver a la esencia de sí mismo, es lograr llegar un despertar al espíritu y sentir el fin de la soledad, la presencia del amor y la felicidad.

El concepto de círculo hace referencia a la igualdad de condiciones humanas, al sentido de pertenecer y sentirse parte del mundo, a conectarse con lo simbólico y lo físico, es retomar el valor de las historias y la experiencia de lo vivido. El círculo abre la posibilidad de comprender que en nuestro interior existen dimensiones como mente, emociones, sentimientos, historias, experiencias, saberes, instinto ancestral y la intuición, que pueden llegar a estar alineadas para recuperar el espíritu mismo grabado desde hace miles de años y comprendido como la capacidad de contactarse con el interior y lograr percibir la conexión con el universo mismo; ser parte del todo, ser efímero, pasajero y eterno.

Nombrarse como hombre o mujer completo no dividido y agradecer para entender el sacrificio que hicieron nuestros antepasados cuando dieron su lucha interna en sus raíces amerindias. 


\section{A MODO DE CIERRE}

Hago una provocación a gozar de un humanismo holístico que puede ser una propuesta decolonial e intercultural con claras raíces amerindias, como la posibilidad para que las universidades latinoamericanas planteen didácticas propias con valores y significados autóctonos para recuperar el saber ancestral, para lograr la transformación de los estudiantes en una posible Inteligencia Espiritual, pensada como la vía de salida de una rígida educación no participativa y vigilada; para propiciar espacios que permitan un encuentro con una transformación interna, que visualice la emancipación de su instinto, de su condición genuina de humanidad atravesada por un dolor necesario y un conocimiento ancestral consciente de su sabiduría interna.

Invitación a profundizar la reflexión desde el aula y desde los espacios que habitan y construyen y no desistir para encontrar El poder de lo humano que emerge de lo divino del ser, cuando este descubre su impotencia en el mundo de lo vivido.

Esta es la premisa que nace de esta vivencia y con la cual cierro, luego de esclarecer que Hegel, en la Fenomenología del espíritu, permite descubrir que tanto las personas como las cosas tienen un origen derivado de un deseo que se concreta en que la historia dada está fundamentada en el ser mismo que la imaginó, y se convierte en algo material para ser usado o posibilitar relacionarse con lo cotidiano. La clave está en volver a la esencia de lo humano, que es el espíritu de todo lo que somos y lo que hacemos, por eso, aunque no seamos conscientes somos espirituales, porque finalmente fuimos deseados por otros.

El espíritu de este mundo es la esencia espiritual impregnada por una autoconciencia que es para sí y que se sabe presente de un modo inmediato como esta autoconciencia que es para sí y que sabe la esencia como una realidad opuesta a ella (Hegel, 1972, p. 287).

Aunque la idea de este filósofo nos remite a pensar que somos aunque no seamos conscientes de ello, esa parte espiritual es la que mueve los deseos del mundo, aunque en ocasiones termine superando lo imaginado o negando lo vivido. Esta ponencia quiere reivindicar los diferentes saberes y agradecer a los mayores el amor, la aceptación y todos los conocimientos que han entregado con sus sacrificios y con las manos que tocaron la tierra para escucharla 
vibrar. Los caminos que abrieron para que encontráramos espacios como este para remembrar los latidos del corazón de la madre tierra.

Si los dioses nos abandonaron, pero para los dioses la soledad de los cielos está llena de promesas humanas, y la tierra es el porvenir del hombre, su alegre morada y su reposo.

\section{REFERENCIAS}

Arias, M. (2015). ¿Sabías que resistir genera toxinas? Elijamos sanar con el Poder Interior. Recuperado de http://www.convivirgrupo.com.ar/bolet_articulos_3_a.htm

Buss, M. (1998). Raíces de la sabiduría. México: International Thomson Editores, S. A. de C. V.

De Sousa, B. (2009). Epistemología del sur: la reinvención del conocimiento y la emancipación social. México. Siglo XXI.

De Sousa, B. (2010). Descolonizar el saber, reinventar el poder. Montevideo: Trilce.

Escobar, A. (2014). Sentirpensar con la Tierra. Nuevas lecturas sobre el desarrollo, territorio y diferencia. Medellín: Fondo Editorial UNAULA.

Fazio, M. (2006). Idas y vueltas de la trascendencia en la Modernidad. Revista de Humanidades, VI(1), 111-133.

Foucault, M. (1967). Le parole e le cose. Milán: Rizzo.

Grof, C., y Grof, S. M. D. (2003). En busca del ser. Guía para el crecimiento personal. Rosario: Nuevo Tiempo.

Guadarrama, P. (2012). Pensamiento filosófico latinoamericano. Humanismo, método e historia. Tomo I. Bogotá: Universidad Católica de Colombia - Planeta.

Hegel, G. W. (1972). Fenomenología del espíritu. La Habana: Editorial de Ciencias Sociales.

Jaramillo, A. (1993). Situación política, económica y jurídica del indio en el Ecuador. En J. Trujillo (Comp.), Indianistas, indianófilos, indigenistas, entre el enigma y la fascinación Quito: Abya Yala - ILDIS.

Kahn, L. (1978). Letteratura e crisi della fede. Roma: Città Nuova.

Krishnamurty, J. (1978). Temor, placer y dolor. México: Orión.

Landa, V. (2011). Pensamientos indígenas en nuestra América, Buenos Aires: CLACSO. Recuperado de bibliotecavirtual.clacso.org.ar/ar/libros/ becas/critica/C01LVazquez 
Mariátegui, J. (1972). El alma matinal y otras estaciones del hombre de hoy. Lima: Biblioteca Amauta.

Mariátegui, J. (1979). 7 ensayos de interpretación de la realidad peruana. Lima: Minerva.

Martínez, M. (1997). El paradigma emergente: hacia una nueva teoría de la racionalidad científica. México: Trillas.

Marx, K. (1969). Zur Kritik der Hegelschen Rechtsphilosophie. Berlín: Hofenberg.

Moraga, F. (2013). Nietzsche y los intelectuales de la izquierda latinoamericana, 1900-1936. Recuperado de https://www.researchgate. net/.../230817085_NIETZSCHE_Y_LOS_INTELECTUALES

Naranjo, C. (2007). Cambiar la educación para cambiar el mundo. Providencia: Espacio Índigo.

Nietzsche, F. (1973). Así habló Zatratustra. Madrid: Alianza Editorial.

Nietzsche, F. (1975). La genealogía de la moral. Madrid: Alianza Editorial.

Reinaga, F. (1970). Manifiesto del Partido Indio de Bolivia. La Paz: Ediciones PIB. 